\title{
Bike speed measurements in a recreational population: validity of self reported speed
}

\author{
Diane C Thompson, Viviana Rebolledo, Robert S Thompson, Alexandra Kaufman, \\ Frederick P Rivara
}

\begin{abstract}
Objective-Speed at the time of a bicycle crash is an important determinant of the amount of energy transmitted. Controlling for speed is thus important in the evaluation of outcomes and effectiveness of intervention strategies. This study was conducted to evaluate the accuracy of self reported speed in a population of recreational cyclists.
\end{abstract}

Methods-Children's and adults' bicycle speeds were measured with a radar gun as they rode along a closed road at weekend recreational events. Cyclists were then stopped and asked to estimate their speed. Measured speed, cyclist's estimate of their speed, age, and sex were documented. Parents were also asked to estimate their child's speed.

Results-One hundred and fifty two cyclists from 4 to 80 years of age participated. Seventy per cent were children 13 years of age or younger. The mean (SD) speed of this group was 8.9 (2.5) $\mathrm{mph}$. Cyclists age 14 and older were traveling at a mean speed of $9.7(2.87) \mathrm{mph}$. Estimated speeds were significantly higher than measured speeds for this older group, but there was no significant difference between mean measured and estimated speeds for the younger riders. There was also no significant difference between measured and estimated speed for males and females. Parents estimated their child's speed quite accurately.

Conclusions-Self reported speeds for children were in close agreement with measured speeds and, thus, are sufficiently accurate to be a useful measure of crash severity in evaluating helmet effectiveness.

(Injury Prevention 1997; 3: 43-45)

Keywords: bicycle; speed; validity of self report.

The severity of injury involving individuals in or on moving vehicles is directly related to the speed at the time of impact. This well known physical principle has been documented for motorcycle, motor vehicle occupant injuries, and motor vehicle-pedestrian collisions. ${ }^{1}$ Speed has been used as one of a series of measures (that is, motor vehicle involvement, damage to cycle, surface impacted) developed to describe the kinetic forces involved in bicycle crashes. Such measures allow for adjustment for confounding in studies of outcome and the effectiveness of injury prevention strategies. Many bike crashes are unwitnessed, and crash reports rely solely on the cyclist's report of speed at the time of the crash. While self reported speed has been used as a measure of severity in several case-control studies of bicycle helmet effectiveness, ${ }^{2-4}$ there is no information reporting riding speeds in recreational populations of children or adults. This study was designed to validate self reported speed estimates of a group of recreational riders consisting primarily of children and their parents.

\section{Methods}

EQUIPMENT AND MEASUREMENT TECHNIQUE We used a radar gun (CMI, Speed Gun) provided by the Seattle Engineering Department, Seattle, Washington to measure bicycle speeds. The gun was calibrated before each use following manufacturer specifications. In addition, a stopwatch method was used to time a sample of riders over a distance of 100 yards. Rider speed was calculated by measuring the time required to cover 100 yards and calculated time was compared with measured speed. We found that the radar gun reading was within $\pm 4 \%$ error at slow speeds $(7 \mathrm{mph}$ and below).

Standardized Engineering Department operation procedures were followed when using the radar gun. The gun was mounted on a surveyor's tripod and positioned 1-2 feet from the bicycle path. This arrangement minimized any interference with bicyclists' travel and provided the research team with sufficient visual clearance to make observations of riders. Two engineering students experienced in the use of the radar gun performed all the measurements. A walkie talkie was used from station \#1 to communicate measured speed and description of the cyclist to the team member positioned at station \#2, a stop sign approximately 100 yards away where cyclists normally stop. One observer, stationed at the radar gun, recorded measured speed and characteristics of the bicyclists (estimated age, gender, helmet use, and cyclist descriptionfor example child with green shirt, blue helmet, black mountain bike) into a hand held tape recorder. The second observer used a clipboard and data collection form to manually

Harborview Injury
Prevention and
Research Center,
Department of
Pediatrics, University
of Washington,
Seattle, WA, USA
DC Thompson
V Rebolledo
A Kaufman
Department of
Preventive Care,
Group Health
Cooperative of Puget
Sound, Seattle, WA,
USA
RS Thompson
Harborview Injury
Prevention and
Research Center,
Departments of
Pediatrics and
Epidemiology,
University of
Washington, Seattle,
WA, USA
FP Rivara
Correspondence to: Ms
Diane C Thompson,
Harborview Injury,
Prevention and Research
Center, 325 Ninth Ave, Box
359960, Seattle, WA 98104-
2499, USA.


record pertinent information on each participant. Cyclists who agreed to participate in the study were asked their age, and how fast they were riding when they passed station \#1. Age and gender were documented but no personal identifiers were recorded. Parents or other adults riding with children under 14 years were asked to estimate their child's speed. The difference between estimated speed and mean measured speed was evaluated using a paired $t$ test with mean difference and $95 \%$ confidence intervals reported.

\section{SETTING}

Measurements were collected at two separate Bicycle Saturday/Sunday events. On these days one major Seattle street is closed to car traffic allowing cyclists to ride freely on the roadway. The road along the lakeshore is flat and largely unobstructed. Sampling was done on two separate weekend days, both of which had warm, sunny weather. Sampling was conducted between 11 and $3 \mathrm{pm}$ each day. The project was approved by the Human Subjects Review Board of the University of Washington.

Table 1 Mean measured speed by sex and age groups

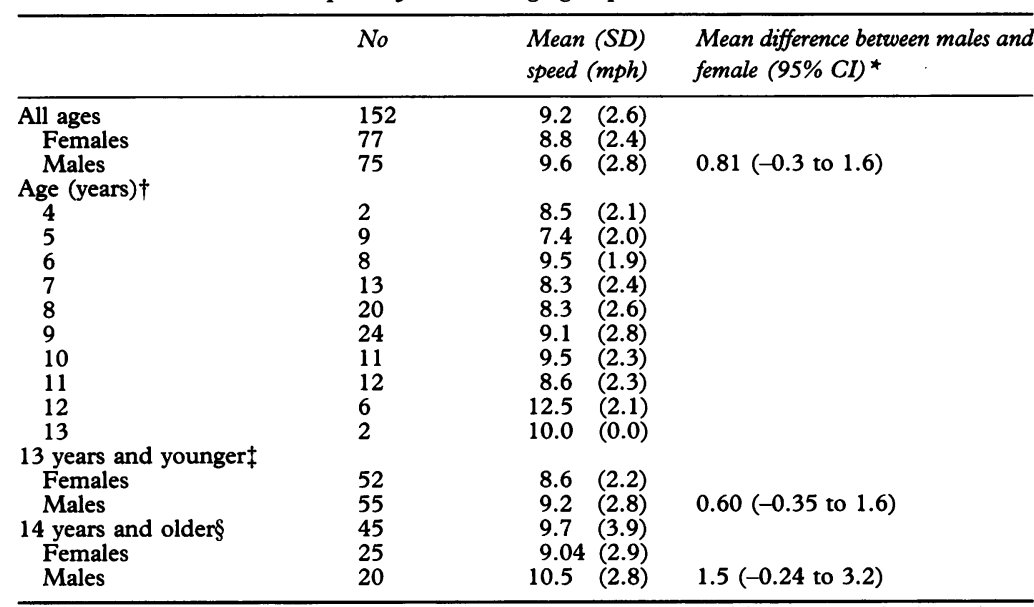

*Unpaired $t$ test assuring equal variance comparing mean speeds of females $v$ males in each age group $(\mathrm{CI}=$ confidence interval).

$\dagger$ There were no differences in riding speed and estimate of speed for cyclists by individual year of age ( $p=0.1$ to 0.9 , depending on specific age).

†There were 11 riders under 6 years of age, eight males and two females. Only two riders were 13 years old, both female.

$\S$ There were three riders aged 15 and 16 , one female and two males.

Table 2 Comparison of measured speed to estimated speed

\begin{tabular}{|c|c|c|c|c|}
\hline \multirow[b]{3}{*}{$\begin{array}{l}\text { All ages } \\
\text { Females } \\
\text { Males } \\
13 \text { years and younger } \\
\text { Females } \\
\text { Males } \\
14 \text { years and older } \dagger \\
\text { Females } \\
\text { Males }\end{array}$} & \multirow{2}{*}{ No } & \multicolumn{2}{|c|}{ Mean speeds (mph) } & \multirow{2}{*}{$\begin{array}{l}\text { Mean difference }(95 \% C I) * \\
\text { (estimate-actual) }\end{array}$} \\
\hline & & Measured (SD) & Estimated (SD) & \\
\hline & $\begin{array}{l}152 \\
77 \\
75 \\
107 \\
52 \\
55 \\
45 \\
24 \\
20\end{array}$ & $\begin{array}{c}9.2(2.6) \\
8.8(2.4) \\
9.6(2.8) \\
8.9(2.5) \\
8.6(2.2) \\
9.2(2.8) \\
9.7(2.9) \\
9.04(2.9) \\
10.5(2.8)\end{array}$ & $\begin{aligned} & 9.3(5.9) \\
& 8.4(3.6) \\
& 10.1(7.6) \\
& 8.7(6.5) \\
& 7.8(3.5) \\
& 9.4(8.4) \\
& 10.7(3.9) \\
& 9.68(3.5) \\
& 11.95(4.1)\end{aligned}$ & $\begin{array}{l}0.11(-0.85 \text { to } 1.1) \\
-0.31(-1.1 \text { to } 0.47) \\
0.55(-1.2 \text { to } 2.3) \\
-0.26(-1.6 \text { to } 1.0) \\
-0.77(-1.8 \text { to } 0.27) \\
0.22(-2.2 \text { to } 2.6) \\
1.0 \text { (0.03 to } 2.0) \\
0.64(-0.41 \text { to } 1.7) \\
1.5 \text { (-0.4 to } 3.3)\end{array}$ \\
\hline $\begin{array}{l}\text { Parent's estimate } \\
13 \text { years and younger }\end{array}$ & 107 & $8.9 \quad(2.5)$ & 8.5 (3.9) & $-0.42(-1.2$ to 0.35$)$ \\
\hline
\end{tabular}

*Paired $t$ test comparing measured speed to estimated speed $(\mathrm{CI}=$ confidence interval.) $\dagger$ Includes three people under 20 years of age; $p=0.04$.

\section{Results}

Altogether 152 cyclists participated, with a mean age of 18 years (range $4-80$ ). The sample was almost equally divided between. males and females (table 1). Mean speeds for each year of age for children 4 to 13 years are shown in table 1. Mean speed for all ages combined was $9.2 \mathrm{mph}$ (median of 9.0, SD 0 ? 2.6 , range $1-15 \mathrm{mph}$ ). Children 13 years an under were traveling at a mean (SD) speed of 8.9 (2.5) $\mathrm{mph}$, while cyclists age 14 and oldey were traveling at a mean speed of $9 . \%$ (2.9) $\mathrm{mph}$ (table 1). The differences betweero the two age groups were not statisticalls significant nor were differences between male and female cyclists. Table 2 displays the meary differences between estimated and measurect speeds along with $95 \%$ confidence intervals fow these values. There were no differences in riding speed and estimate of speed for cyclistsu by individual year of age nor by age groups Parents were able to accurately estimate their child's speed, whereas cyclists 14 and olde overestimated their speed by approximatels $1 \mathrm{mph}$.

\section{Discussion}

The majority of the bicyclists in this recreas tional population were riding at moderate speeds, between 5 and $15 \mathrm{mph}$. Children if this population were riding at a mean speed of $8.9 \mathrm{mph}$, with speeds ranging from $2 \mathrm{mph} t \underset{\overrightarrow{ }}{\vec{\sigma}}$ $15 \mathrm{mph}$. These speeds are slightly slower than those measured by Neathery and Diolate (unpublished data, 1993), although the frequency distribution of observed speeds for a $\frac{\overline{\mathrm{A}}}{\mathrm{E}}$ of their riders $(n=363)$ clustered around 12 $15 \mathrm{mph}$. They recorded a mean speed of $13 \mathrm{mph}$ for adults and $9.6 \mathrm{mph}$ for children compared with $9.7 \mathrm{mph}$ for riders age 14 and older and $8.9 \mathrm{mph}$ for children in our study The Neathery and Diolata study measured actual speed and did not stop the cyclists for any other information; therefore, rider age was estimated. Children composed $6 \%(n=23)$ of their cycling population while $70 \%$ of ous population were children under 14 years of age. Neither study completely captured the universe of cyclists. Their study measuredy speeds of cyclists on a bike path, used for recreational purposes as well as commuting our study was performed when a 3 mile portion of a city street was blocked off for use b recreational cyclists. Routine commuting of recreating cyclists who use city streets weres therefore, probably underrepresented in oufo measurements. In addition, the cyclists in oup study were riding on a roadway that was close to traffic to encourage safe recreational cycling $\vec{B}$ while Neathery and Diolata's measurements were taken on mixed use (bicycle, pedestrian roller blades) pathways. Most of the adults ito this study sample were accompanying a chils. rider. Parents, as well as other adult cyclists may ride more slowly when children are present. Recall bias after a bike crash could operate in either direction resulting in a under or over estimate of speed of travel. Cyclists in this study were asked to estimate their speed in 
a non-crash situation, possibly giving more accurate results than would apply for cyclists involved in a crash.

This study indicates that both children and their parents are able to accurately estimate children's riding speeds, although teens and adults slightly overestimate their speed. However, within the broad range of $<5 \mathrm{mph}$ and 5 to $15 \mathrm{mph}$, estimated speeds agree quite closely with measured speeds. Further measurements of commuting and day-to-day recreational cyclists are needed to ascertain whether self estimated cyclists speeds over $15 \mathrm{mph}$ are also accurate.

In conducting studies evaluating bicycle injury prevention strategies, it is important that efforts be made to assure the comparability of the crash forces experienced by cyclists in different groups. Several published studies have made no such attempts to take these factors into accounts, leaving the reader unsure of the comparability of the case and control groups. ${ }^{5-7}$ The present study indicates that for speeds commonly traveled (that is under $15 \mathrm{mph}$ ), self reported speeds are reasonably accurate. Self reported speed may be useful therefore, as one measure of crash severity when evaluating helmet effectiveness or other bicycle injury prevention measures.

Finally, the techniques used in this study may be applicable to the further study of injury prevention strategies for bicycling. Self reported speed should be investigated as a risk factor for crash and injury. If found to be so, various strategies could be used to separate slower from faster cyclists or develop other strategies to decrease speed related injuries.

This work was supported by a grant from the Snell Memorial Foundation, 6731 A 32nd St, North Highlands, CA 95660

The authors are indebted to Mike Neathery and James Swantz, engineering students at the University of Washington, Seattle, Washington who performed all the speed measurements. Mike Neathery and Robert Diolata provided us with (lilt 363 bicyclists which were measured on a multiuse trail system. Our thanks to Larry L Sundblad, Bicycle Saturday/Sunday Coordinator for the Seattle Parks Department for allowing us to conduct the
study. We are also indebted to Robert Roseburg of the Seattle study. We are also indebted to Robert Roseburg of the
Engineering Department for lending us the radar gun.

1 Miltner E, Salwender HJ. Influencing factors on the injury severity of restrained front seat occupants in car-to-headon collisions. Accid Anal Prev 1995; 2: $143-50$.

2 Thompson RS, Rivara FP, Thompson DC A case-control study of the effectiveness of bicycle safety helmets. $N$ Engl $\Im$ Med 1989; 320: $1361-7$

3 Thomas S, Acton C, Nixon J, Battistutta D, Pitt WR, Clark $R$. Effectiveness of bicycle helmets in preventing head injury in children: case-control study. $B M \Im$ 1994; 380: injury in

4 Mamaris C, Summers CL, Browing C, Palmer CR. Injury patterns in cyclists attending an accident and emergency department: a comparison of helmet wearers and nonwearers. $B M \mathcal{F}$ 1994; 308: $1537-40$.

5 McDermott FT, Lane JC, Brazenor GA, Debney EA. The effectiveness of bicyclist helmets: a study of 1710 casualties. F Trauma 1993; 34: 834-45.

6 Spaite DW, Murphy M, Criss EA, Valenzuela TD, Meislin HW. A prospective analysis of injury severity among helmeted and nonhelmeted bicyclists involved in collisions with motor vehicles. F Trauma 1991; 31: 1510-6.

7 Acton CHC, Nixon JW, Clark RC. Bicycle riding and oral maxillofacial trauma in young children. Med $\mathcal{F}$ Aust 1996; 165: $249-51$.

\section{Unusual sporting injuries}

A somewhat whimsical review of unusual ways sports may be injurious, entitled 'Warning: Fine Art Ahead', includes the danger of eye injuries to squash players (prevented by the use of goggles), gynaecological complications of backwards falls in water skiing (prevented by wet suits), and twisted intestines of hula hoopers (prevented by avoiding immoderate uses of no longer popular hoops). The writer concludes that advertisers should throw the danger angle away because 'jeopardy can be anywhere, any time' (S Castles, The Big Issue) (IS).

\section{Bad weekend for Victorian sport}

Two sportsmen, a 19 year old basketballer and a 24 year old rugby player, both Australian, were killed on the same day. The basketballer was killed when the ring fell on his head after slam-dunking the ball and holding onto the ring. The ring snapped. The rugby player collapsed in the final minutes of a cup game after making a try saving tackle (The Age, 8 July 1996) (IS).

\section{State-by-state mortality facts}

A new publication notes that motor vehicle deaths still outrank other injuries and diseases as the leading cause of death among children and teenagers 1-19 years old in the US. The study comes from the Johns Hopkins Center for Injury Research and Policy. Injuries to Children and Teenagers by SP Baker et al, is available from the Insurance Institute for Highway Safety, 1005 N Glebe Rd, Arlington, VA 22201, USA. 